\title{
Dynamics of PCB transfer from mother to pup during lactation in UK grey seals Halichoerus grypus: differences in PCB profile between compartments of transfer and changes during the lactation period
}

\author{
Cathy Debier ${ }^{1}$, Paddy P. Pomeroy ${ }^{3}$, Cédric Dupont ${ }^{4}$, Claude Joiris ${ }^{5}$, \\ Vinciane Comblin ${ }^{4}$, Eric Le Boulengé ${ }^{2}$, Yvan Larondelle ${ }^{1, *}$, Jean-Pierre Thomé ${ }^{4}$ \\ ${ }^{1}$ Unité de Biochimie de la Nutrition (BNUT), and ${ }^{2}$ Unité de Biométrie et analyse des données (BIOM), Université catholique \\ de Louvain, Croix du Sud 2/8 and 2/16, 1348 Louvain-la-Neuve, Belgium \\ ${ }^{3}$ NERC Sea Mammal Research Unit, Gatty Marine Laboratory, University of St Andrews, St Andrews KY16 8LB, Scotland, UK \\ ${ }^{4}$ Laboratoire d'Ecologie animale et d'Ecotoxicologie, Institut de Zoologie, Université de Liège, Quai Van Beneden 22, \\ 4020 Liège, Belgium \\ ${ }^{5}$ Laboratory for Ecotoxicology and Polar Biology, Free University of Brussels, Pleinlaan 2, 1050 Brussels, Belgium
}

\begin{abstract}
The composition of the PCB mixture which is transferred from mother to pup in grey seals Halichoerus grypus throughout lactation was measured in the successive compartments of transfer: maternal blubber, maternal serum, milk and pup serum. Mother-pup pairs were captured regularly between birth and weaning on the Isle of May, Scotland. The PCB profiles of the different compartments of transfer consisted mainly of congeners 153,138, 180, 187, 170 and 101, which made up $85 \%$ of the total PCB burden. Outer blubber contained higher relative concentrations $\left(\mathrm{R}_{153}\right)$ of hepta-, octa-, and nona-chlorinated congeners (higher chlorinated congeners) than inner blubber, at both early ( $\leq 5 \mathrm{~d}$ ) and late $(\geq 11 \mathrm{~d}$ ) lactation. There was no change in the composition of the outer blubber layer between early and late lactation, while in the inner blubber, there was a slight increase in the $\mathrm{R}_{153}$ of higher chlorinated congeners at late lactation. In maternal serum, profiles changed towards having a higher proportion of higher chlorinated congeners as lactation progressed, but in milk, the PCB pattern stayed constant throughout lactation. Surprisingly, in pup serum profiles also changed towards higher $\mathrm{R}_{153}$ of higher chlorinated congeners at late lactation compared to early lactation, which was different to the pattern observed in milk. In all body compartments, higher proportions of higher chlorinated congeners were associated with higher concentrations of total PCBs. Maternal blubber and pup serum contained a higher $\mathrm{R}_{153}$ of higher chlorinated congeners than milk and, to a lesser extent, maternal serum. Thus biomagnification of the higher chlorinated congeners was recorded in pup serum.
\end{abstract}

KEY WORDS: Grey seal · Halichoerus grypus $\cdot$ PCBs $\cdot$ Profile $\cdot$ Milk $\cdot$ Serum $\cdot$ Blubber $\cdot$ Lactation

- Resale or republication not permitted without written consent of the publisher

\section{INTRODUCTION}

Man-made pollutants such as polychlorinated biphenyls (PCBs) have been identified world-wide in the environment and particularly in oceans, which appear to play the role of sinks for the accumulation of organochlorine pollutants. Due to their high lipophilic-

*Corresponding author. Email: larondelle@bnut.ucl.ac.be ity as well as their resistance to physical, chemical and biological degradation, PCBs bioaccumulate up marine food chains (Muir et al. 1988).

PCBs induce a variety of toxic effects, such as immunotoxicity, neurotoxicity, carcinogenicity, developmental impairment and reproductive problems (Safe 1994, Ross et al. 1996, Bard 1999). Congeners are 
metabolized differently, depending on the degree of chlorination as well as on the structure of the molecule (Safe 1994). This biotransformation occurs through the activation of cytochrome P-450-dependent monooxygenases. Non-planar congeners, such as PCB-153, $-138,-180$, and -187 , are the most persistent, and accumulate in fatty tissues (Boon et al. 1994, Wolkers et al. 1998, Ross 2000). Metabolism and excretion rates of PCBs decrease with the degree of chlorination (Safe 1994, Bard 1999). PCB-153, a di-ortho hexa-CB, is extremely persistent and accumulates up the food chain. It is present in all mammalian tissues and has been chosen as a reference congener to evaluate the metabolic or biomagnification index of the other congeners (Boon et al. 1994, Hugla et al. 1995, Wolkers et al. 1998).

The general profile of PCBs in tissues is relatively similar among marine mammals and is dominated by PCB-153, -138 and -180 (Addison \& Brodie 1987, Law et al. 1989, Bacon et al. 1992, Hong et al. 1996, Pomeroy et al. 1996, Kleivane et al. 1997, Wolkers et al. 1998, Andersen et al. 2001). However, inter-specific differences are observed and have been explained by the availability of PCBs in food as well as subsequent biotransformation and enzyme-mediated metabolism and excretion (Boon et al. 1994, Tanabe et al. 1994, Mössner \& Ballschmiter 1997, Bernt et al. 1999, Ross 2000, Andersen et al. 2001).

Among the same marine mammal species, PCB patterns can vary to some extent with tissue and age. Indeed, the PCB profile changes from one tissue to the other as a result of the physicochemical properties of the different congeners and of the lipid composition of the tissue considered. A lower proportion of highly chlorinated congeners, which are more lipophilic and less polar, has been noticed in seal blood, which contains more polar lipids compared to blubber (Jenssen et al. 1996, Bernhoft et al. 1997). Similarly, the selective transfer of congeners through the milk, coupled with preferential intestinal absorption and tissue storage, as well as with low metabolism and excretion abilities, explain why newborns present different PCB profiles from their mothers (Bernhoft et al. 1997, Beckmen et al. 1999).

A pup receives its initial PCB burden in the womb, and then a potentially large quantity of PCBs is ingested by the pup through milk during lactation. The composition of this burden in terms of congeners must be taken into account to assess the possible impairment that could be induced by an acute exposure to PCBs during the early stage of life. This article is part of a larger study on the dynamics of transfer of PCBs from mother to pup in grey seals from the Isle of May during lactation. The quantification of PCB transfer from one body compartment to the other (maternal blubber $\rightarrow$ maternal serum $\rightarrow$ milk $\rightarrow$ pup serum) throughout lactation is presented in a companion paper (Debier et al. 2003, this issue). The present paper deals with the qualitative aspects of this transfer. The relative concentrations of individual congeners compared to the concentration of PCB-153 $\left(\mathrm{R}_{153}\right)$ have been followed throughout lactation.

\section{MATERIALS AND METHODS}

Field techniques. The study was conducted on the Isle of May, Scotland (56 $12^{\prime} \mathrm{N}, 2^{\circ} 32^{\prime} \mathrm{W}$ ), in November 1998 and 2000. All data on the mother-pup pairs studied, as well as on the samples collected, are presented in Debier et al. (2003). All animal handling, as well as milk, blood and blubber collection, are described elsewhere (Debier et al. 2002, 2003).

Chemical analyses. Sample preparation and PCB analysis were performed as detailed in Debier et al. (2003). Twenty-six congeners were measured (IUPAC $8,18,28,44,52,66,70,87,95,101,105,110,118,128$, $138,149,153,156,170,180,183,187,194,195,206$, 209).

Data analyses. Calculated values: In order to compare the PCB profiles between body compartments and throughout lactation in the same body compartment, we expressed the concentrations of the different congeners as a proportion of the appropriate concentration of PCB-153, which is the most persistent and thus generally the most abundant congener found in biological tissues. We will refer to ' $\mathrm{R}_{153}$ ' or 'proportion' to describe this ratio.

The relative biomagnification factor from prey/food source to the consumer, referred to as 'relative ratio' or $\mathrm{R}_{\mathrm{rel}(\mathrm{PCBx}) \text {, is calculated by using the equation (Boon et }}$ al. 1994):

$$
\mathrm{R}_{\mathrm{rel}(\mathrm{PCBx})}=\mathrm{R}_{153(\mathrm{PCBx})} \text { consumer } / \mathrm{R}_{153(\mathrm{PCBx})} \text { diet }
$$

In this case, milk was used as the food source and the pup's serum as the consumer, according to Beckmen et al. (1999). Thus a $R_{\text {rel(PCBx) }}$ significantly $>1$ (i.e. a $95 \%$ confidence interval lower limit of $>1$ ) indicates biomagnification from milk to pup serum (Wolkers et al. 1998, Beckmen et al. 1999).

Statistical tests: Results were analyzed using the GLM procedure (SAS/STAT 1990). The statistical treatments were carried out on groups of congeners, according to their degree of chlorination compared to PCB-153. The first group is referred to as tetra- and penta-CBs (PCB-52,-101,-110, and -118), which have lower degrees of chlorination than PCB-153. The second group is referred to as hexa-CBs (PCB-128, $-138,-149$ and -156$)$, which have the same degree of chlorination as PCB-153. The third group is referred to 
as hepta-, octa-, and nona-CBs (PCB-170, -180, -183, -187, -194,-195,-206, and -209), which have higher degrees of chlorination than PCB-153. The dependent variable was the $R_{153}$ of one of these groups of PCB congeners.

Changes throughout lactation: Milk and serum samples. Two variables were included in the model analysis of variance: individual (mother or pup) and age of pup. Age of pup was considered as a continuous variable because milk and blood samples were collected at different lactation stages. We used a 2-way ANCOVA, crossed design.

Blubber samples. Blubber biopsies were taken only at early and late lactation for all females and were divided into 2 layers (inner and outer blubber). Variations of $\mathrm{R}_{153}$ in the blubber were analyzed, using a 3-way mixed ANOVA, crossed design, with the following factors: individual, stage of lactation (early or late), and blubber layer (inner or outer). Stage of lactation and blubber layer were combined into a single 4-level factor, whose levels could then be compared pairwise, using Bonferroni's $t$-test for paired samples.

Comparisons between body compartments: The different compartments of transfer were compared. We thus used the mother-pup pairs for which we had analysed samples in all the compartments: maternal inner blubber, maternal serum, milk, and pup serum. We therefore focused on the samples of 2000, as blubber biopsies were performed only during that breeding season (Debier et al. 2003). PCB concentration variations in the blubber were analyzed using a 3-way mixed ANOVA, crossed design, with the following factors: individual (mother-pup pair), stage of lactation (early or late), and compartment. Stage of lactation and compartment were combined into a single 8-level factor, whose levels could then be compared pairwise, using Bonferroni's $t$-test for paired samples.

We will refer to 'early' and 'late' lactation for the periods from Days 0 to 5 and from Days 11 to 20, respectively.

\section{RESULTS}

\section{General PCB profiles}

In each body compartment, the major congeners were PCB-153, -138, -180, -187, -170 and -101. These congeners accounted for more than $85 \%$ of total PCB concentrations. Among the other congeners quantified, PCB-52, -118, -128, -149, -194, -195, -183 and -206 were found regularly in measurable amounts whereas PCB- 95, -105, -110, and -156 could be quantified in a few samples only. Congener 209, a deca-CB, has been found in several samples and especially in blubber samples. Only the most frequently encountered congeners are presented in the figures.

\section{Changes throughout lactation}

\section{Maternal blubber}

The results of the ANOVA are presented in Table 1. PCB-52 (a tetra-CB) was not quantified in inner and outer blubber samples. There was a significantly higher proportion of hepta, octa, and nona-CBs in outer blubber than in inner blubber at both early and late lactation (Table 1, Figs. 1 \& 2). At early lactation, the $R_{153}$ of penta-CBs was higher in outer than inner blubber, but this difference disappeared at late lactation. The $\mathrm{R}_{153}$ of hexa-CBs did not vary between inner and outer blubber. The proportions of the different groups of congeners did not vary significantly between early and late lactation in either inner or outer blubber (Table 1). The only exception was for the $\mathrm{R}_{153}$ of pentaCBs, which decreased significantly between early and late lactation in the inner blubber. A slight increase of several hepta-, octa-, and nona-CBs, such as PCB-180, was observed in the inner blubber (Fig. 1A).

\section{Maternal serum, milk and pup serum}

The results of the ANCOVA are presented in Table 2. PCB-52 was detected in the serum samples but could not be correctly quantified due to an interference with the SPE-C18 column used for the PCB extraction from the matrix (see Debier et al. 2003 for the method). The $\mathrm{R}_{153}$ of hepta-, octa-, and nona-CBs increased between early and late lactation in maternal and pup serum, while it stayed constant in milk (Table 2, Figs. 1 \& 2). Concerning the other groups of chlorination, tetra- and

Table 1. Halichoerus grypus. ANOVA of the effect of individual, time (early, 1, or late, 2, lactation) and blubber layer (inner, $\mathrm{IB}$, or outer, OB) on the $\mathrm{R}_{153}$ of $\mathrm{PCB}$ congeners in blubber. $\mathrm{Cl}$ 4-5 refers to tetra- and penta-CBs, $\mathrm{Cl}-6$ refers to hexa-CBs (other than PCB-153), and $\mathrm{Cl} 7-9$ refers to hepta-, octa-, and nona-CBs. For each group of congeners (each line of the table), same letters are not significantly different (i.e. $p>0.05$; pairwise Bonferroni comparisons). $p$-values are given for the differences between individuals. The interaction between individual and the factor-combining layer and period of lactation was not testable

\begin{tabular}{|lrcccc|}
\hline Group of PCBs & Individual & IB 1 & IB 2 & OB 1 & OB 2 \\
\hline Cl $4-5$ & 0.05 & a & b & b & b \\
Cl 6 & $<0.01$ & a & a & a & a \\
Cl $7-9$ & $<0.01$ & a & a & b & b \\
\hline
\end{tabular}



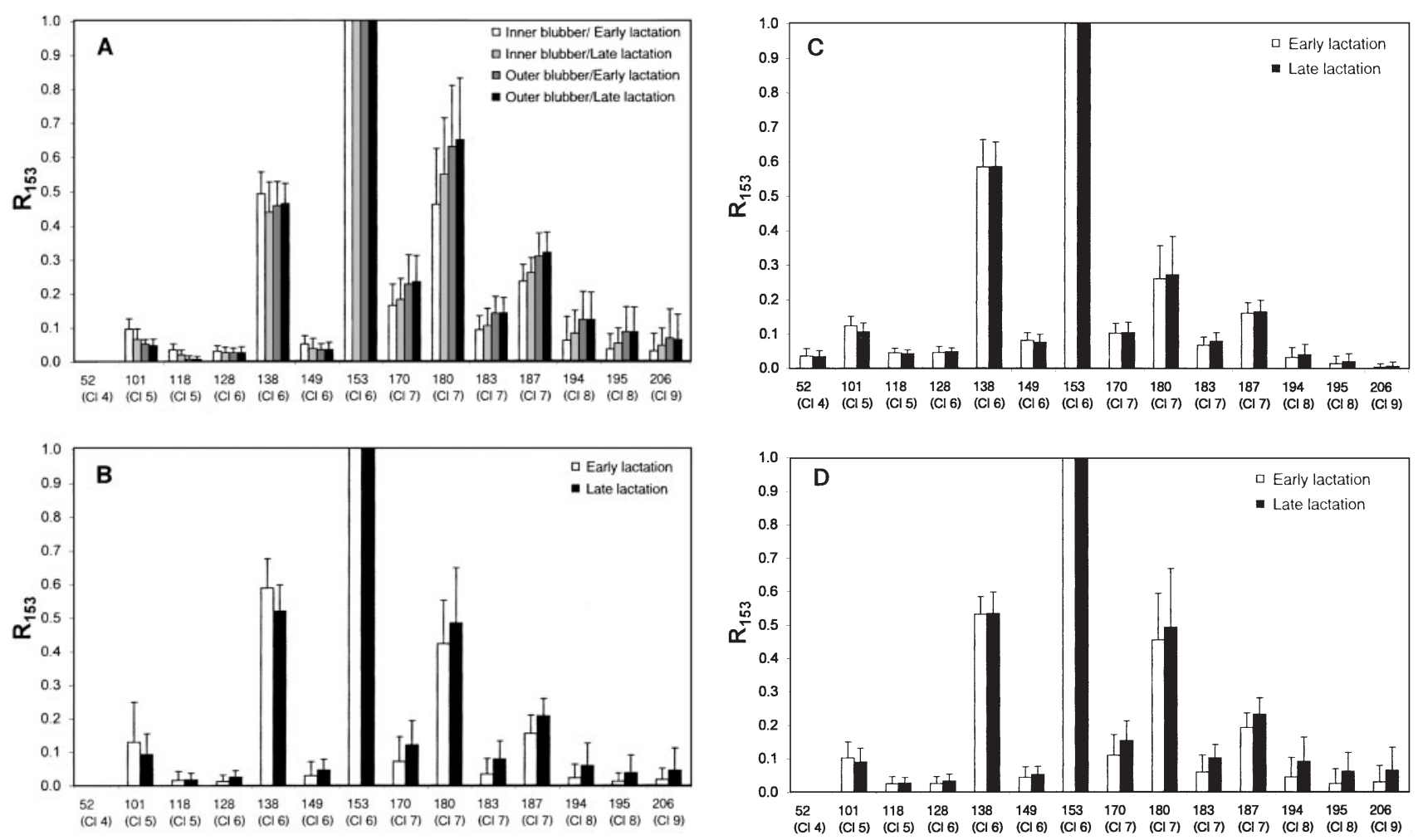

PCB congener IUPAC nr. (Chlorination degree)

Fig. 1. Halichoerus grypus. $\mathrm{R}_{153}$ of PCB congeners at early and late lactation in (A) maternal inner and outer blubber, (B) maternal serum, (C) milk, and (D) pup serum

penta-CBs were found in higher proportions at early lactation compared to late lactation in milk, while no significant difference was noticed in the 2 other compartments of transfer (Table 2, Figs. $1 \& 2$ ). The $\mathrm{R}_{153}$ of

Table 2. Halichoerus grypus. ANCOVA (p-values) of the effect of individual and time (age of pup) on the $\mathrm{R}_{153}$ of $\mathrm{PCB}$ congeners in maternal serum, milk and pup serum. $\mathrm{Cl}$ 4-5 refers to tetra- and penta- $\mathrm{CBs}, \mathrm{Cl}-6$ refers to hexa-CBs (other than PCB-153), and $\mathrm{Cl} 7-9$ refers to hepta-, octa-, and nona-CBs

\begin{tabular}{|lrrc|}
\hline $\begin{array}{l}\text { Group of } \\
\text { PCBs }\end{array}$ & $\begin{array}{c}\text { Individual } \\
\text { (I) }\end{array}$ & $\begin{array}{c}\text { Age of } \\
\text { pup (A) }\end{array}$ & $\begin{array}{c}\text { Interaction } \\
(\mathrm{I} \times \mathrm{A})\end{array}$ \\
\hline Maternal serum & & & \\
Cl 4-5 & 0.83 & 0.86 & 1.00 \\
Cl 6 & 0.88 & 0.57 & 0.99 \\
Cl 7-9 & $<0.01$ & $<0.01$ & 0.70 \\
Milk & & & \\
Cl 4-5 & $<0.01$ & $<0.01$ & $<0.01$ \\
Cl 6 & $<0.01$ & 0.32 & 0.07 \\
Cl 7-9 & $<0.01$ & 0.18 & 0.93 \\
Pup serum & & & \\
Cl 4-5 & 0.20 & 0.66 & 0.84 \\
Cl 6 & 0.54 & 0.32 & 0.80 \\
Cl 7-9 & $<0.01$ & $<0.01$ & 0.03 \\
\hline
\end{tabular}

hexa-CBs did not change significantly throughout lactation in maternal serum, milk and pup serum (Table 2, Figs. 1 \& 2).

\section{PCB profile and total PCB concentration}

The $\mathrm{R}_{153}$ of hepta-, octa-, and nona-CBs increased with the rise of total PCB concentrations in all body compartments. Correlation coefficients between the $\mathrm{R}_{153}$ of hepta-, octa-, and nona-CBs and the concentrations of total PCBs were $0.68(\mathrm{p}<0.01)$ in maternal blubber, $0.90(p<0.01)$ in maternal serum, 0.78 $(p<0.01)$ in milk, and $0.74(p<0.01)$ in pup serum. The high inter-individual variability in the PCB profiles paralleled the variability in the total PCB concentrations among individuals (Tables 1 \& 2).

\section{Changes in PCB profile between body compartments}

The results of the ANOVA are presented in Table 3. The $\mathrm{R}_{153}$ of hepta-, octa-, and nona-CBs varied greatly between compartments, especially at late lactation (Fig. 3). Maternal inner blubber contained significantly 
Table 3. Halichoerus grypus. ANOVA of the effect of individual, time (early, 1, or late, 2, lactation) and compartment of transfer (maternal inner blubber, IB; maternal serum, $\mathrm{MS}$; milk, $\mathrm{M}_{\text {; }}$ pup serum, $\mathrm{PS}$ ) on the $\mathrm{R}_{153}$ of PCB congeners. $\mathrm{Cl}$ 4-5 refers to tetra- and penta-CBs, Cl-6 refers to hexa-CBs (other than PCB153), and Cl 7-9 refers to hepta-, octa-, and nona-CBs. For each group of congener (line of the table), same letters are not significantly different (i.e. $p>0.05$; pair-wise Bonferroni comparisons). p-values are given for the differences between individuals. The interaction between individual and the factor combining layer and period of lactation was not testable

\begin{tabular}{|lccccccccc|}
\hline Group of PCBs & Individual & IB1 & IB2 & MS1 & MS2 & M1 & M2 & PS1 & PS2 \\
\hline Cl 4-5 & 0.82 & a,b & b,c & c & c & a & a & b,c & b,c \\
Cl 6 & 0.05 & a,b & b & a,b & b & a,b & a & a,b & a,b \\
Cl 7-9 & $<0.01$ & a,b & a & c & b,c & c & c & b,c & a,b \\
\hline
\end{tabular}

body stores. The fat content of the milk comes mainly from the mobilization of blubber, which also liberates PCBs in the serum of the mother and then in the milk. The general PCB pattern reported in this study agrees broadly with existing literature on phocid seals (e.g. Espeland et al. 1997, Kleivane et al. 1997).

The PCB profile in grey seal tissues during lactation appeared to vary, to some extent, with time of lactation. The main dynamics in the pattern was observed for the $R_{153}$ of hepta-, octa-, greater proportions of this type of congener than milk and maternal serum, at both early and late lactation (Table 3, Fig. 3). Proportions in maternal inner blubber were, however, not significantly higher than in pup serum. At late lactation, milk contained the lowest proportion of hepta-, octa-, and nona-CBs (Table 3, Fig. 3). The proportions of the hexa-CBs did not vary between compartments at early lactation (Table 3, Fig. 3). However, at late lactation there was a greater $\mathrm{R}_{153}$ of hexaCBs in milk than in maternal inner blubber and maternal serum (Table 3). The highest proportion of tetraand penta-CBs was found in milk (Table 3, Fig. 3): this was significantly higher than in maternal and pup serum at both early and late lactation, and higher than in maternal inner blubber at late lactation.

When only mother-pup pairs captured at Day 0 were considered, the $\mathrm{R}_{153}$ of the different groups of congeners were similar between mother and pup at Day 0 (Fig. 4A). Conversely, at late lactation, hepta-, octa-, and nona-CBs appeared to be present in higher proportions in pup serum than in maternal serum (Fig. 4B). However, these variations were not significant $(p>0.05)$.

\section{Biomagnification from milk to pup serum}

At early lactation, a $\mathrm{R}_{\mathrm{rel}(\mathrm{PCBx})}$ significantly $>1$, indicating biomagnification, was observed for PCB-180, -187, and -206 (range: 1.8 for PCB-180 to 4.4 for PCB-206), while at late lactation, it occurred for PCB-170, -180, $-183,-187,-195,-194,-206$ (range: 1.2 for PCB-183 to 7.6 for PCB-206). The other congeners (PCB-101, $-110,-149,-118,-138,-128)$ presented a $\mathrm{R}_{\mathrm{rel}(\mathrm{PCBx})}<1$ at both early and late lactation.

\section{DISCUSSION}

Grey seal mothers in the UK fast during lactation. Milk constituents are thus entirely derived from their
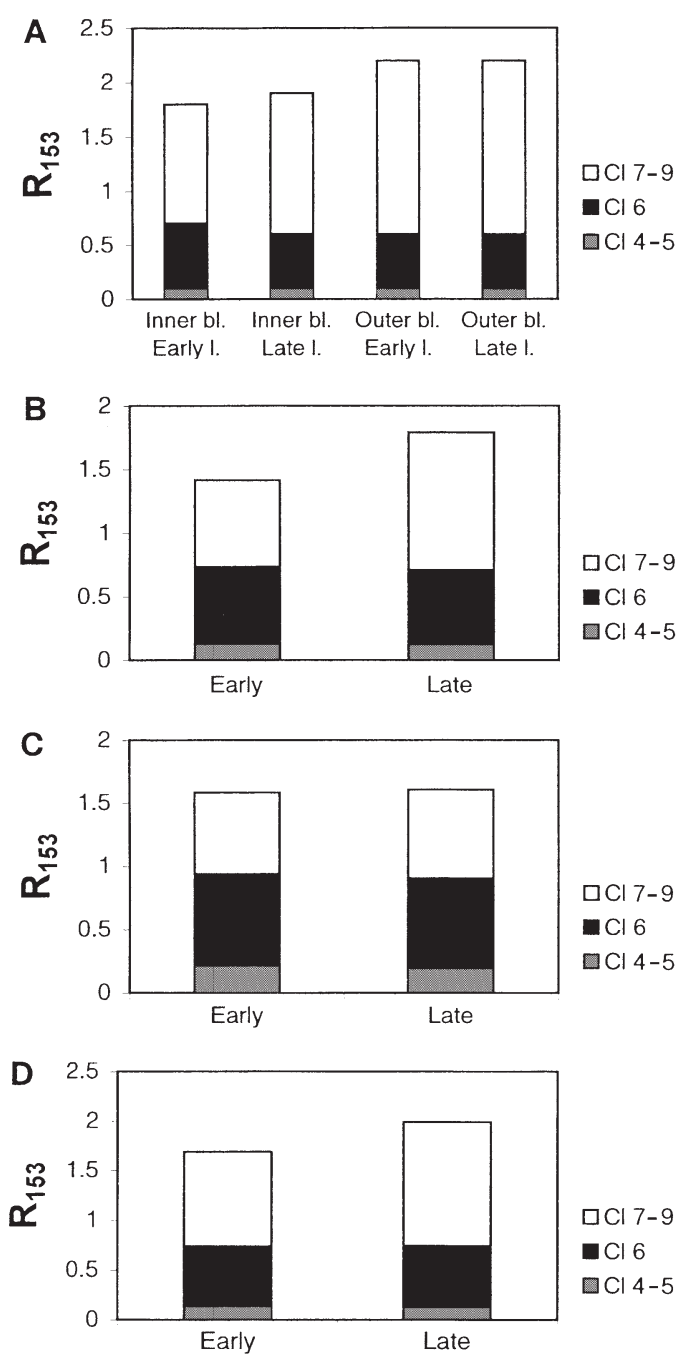

Fig. 2. Halichoerus grypus. $\mathrm{R}_{153}$ of groups of PCB congeners at early and late lactation in (A) maternal inner and outer blubber, (B) maternal serum, (C) milk, and (D) pup serum. The groups have been formed according to their chlorination degree compared to PCB-153. Cl 4-5 refers to tetra- and penta-CBs, $\mathrm{Cl}$ 6 refers to hexa-CBs other than PCB-153, and Cl 7-9 refers to hepta-, octa-, and nona-CBs. bl: blubber; 1: lactation 

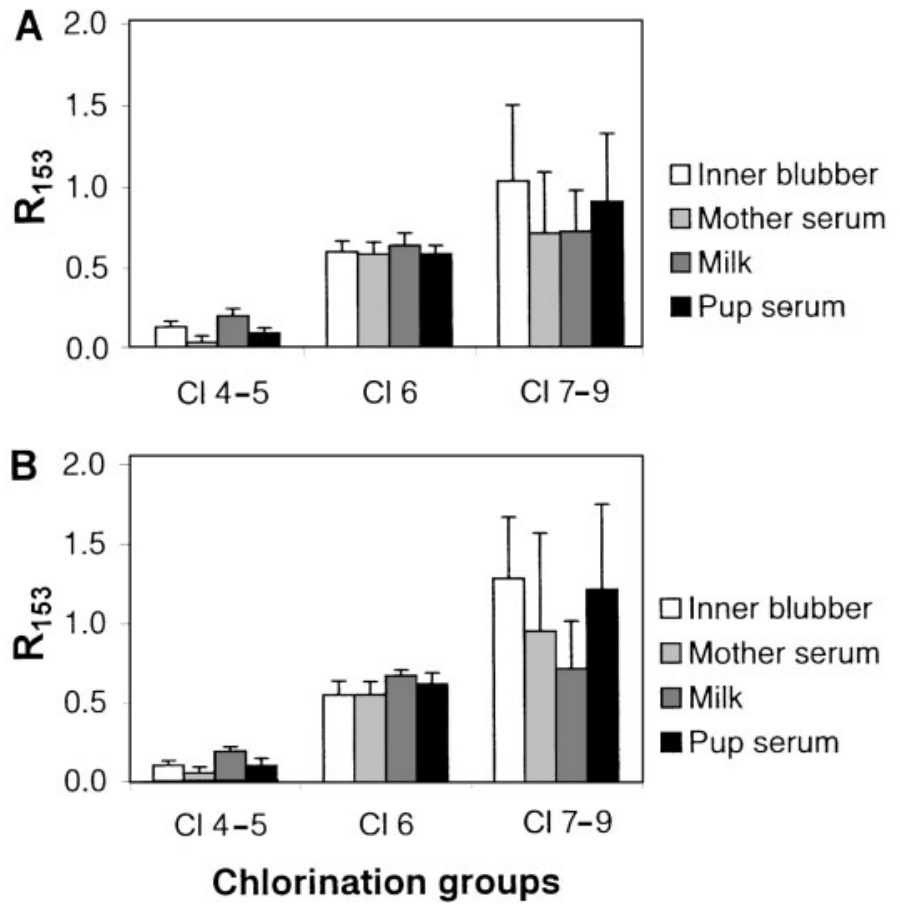

Fig. 3. Halichoerus grypus. $\mathrm{R}_{153}$ of groups of PCB congeners in the different compartments of transfer: maternal inner blubber, maternal serum, milk and pup serum at (A) early and (B) late lactation. The groups have been formed according to their chlorination degree compared to PCB-153. Cl 4-5 refers to tetra- and penta-CBs, $\mathrm{Cl} 6$ refers to hexa-CBs other than PCB-153, and Cl 7-9 refers to hepta-, octa-, and nona-CBs

and nona-CBs. The proportion of these highly chlorinated congeners increased significantly between early and late lactation in maternal serum. Conversely, milk levels remained constant. The absence of parallelism between the dynamics observed in milk and maternal serum suggests either the existence of a barrier at the mammary gland against higher chlorinated PCBs or that the lipid fraction present in the milk has a greater affinity for the lower chlorinated PCBs. Surprisingly, the PCB pattern in pup serum changed towards an increase in the $\mathrm{R}_{153}$ of hepta-, octa- and nona-CBs as lactation progressed. A selective absorption of the higher chlorinated congeners across the gastrointestinal mucosa may occur, as suggested for PCB-180 in northern fur seal pups (Beckmen et al. 1999). This phenomenon might also be explained by a greater deposition of congener 153 in pup tissues compared to the higher chlorinated congeners (hepta-, octa- and nona-CBs). These congeners tend to accumulate in serum with time, even without any modification in the composition of the diet. The fact that hexa-CBs did not exhibit a clear pattern, compared to PCB-153 (another hexa-CB) in the different body compartments as lactation progressed, revealed that the degree of chlori-
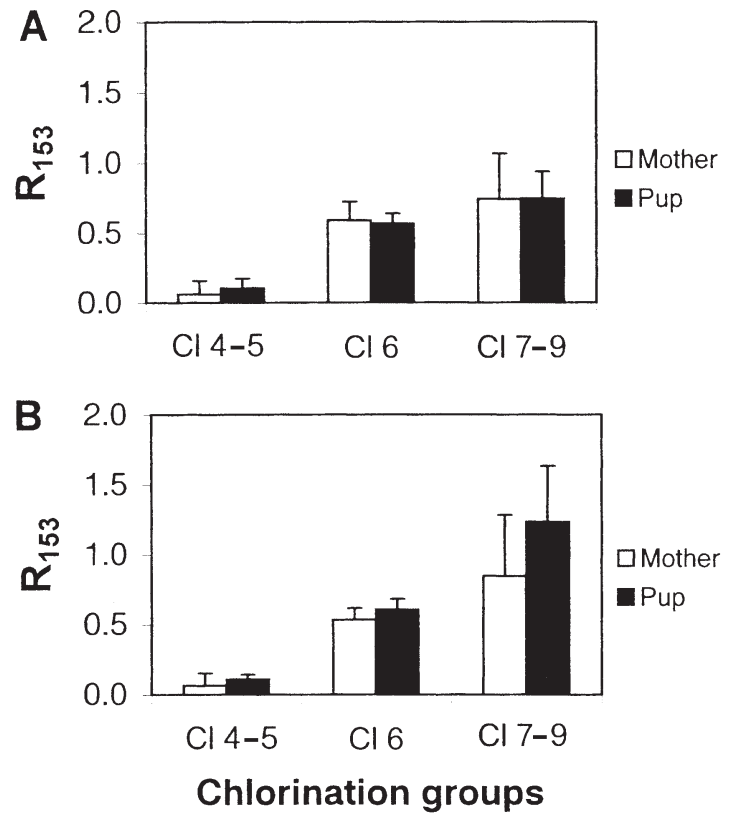

Fig. 4. Halichoerus grypus. $\mathrm{R}_{153}$ of groups of PCB congeners in maternal serum and pup serum at (A) Day 0 and (B) late lactation. The groups have been formed according to their chlorination degree compared to PCB-153. Cl 4-5 refers to tetra- and penta-CBs, $\mathrm{Cl} 6$ refers to hexa-CBs other than PCB-153, and Cl 7-9 refers to hepta-, octa-, and nona-CBs

nation was probably the major factor dictating the dynamics of the $\mathrm{R}_{153}$ during lactation.

In all compartments of transfer, including blubber, the dynamics of total PCBs was accompanied by a change in the PCB profile. Indeed, more contaminated individuals presented greater relative amounts of highly chlorinated congeners compared to less contaminated ones. A shift of the PCB pattern towards the higher chlorinated PCBs in individuals having higher total PCB levels has already been reported in the literature for non-lactating marine mammals (Heidmann et al. 1992, Wolkers et al. 1998, Cleemann et al. 2000, Andersen et al. 2001). The authors observed that the degree of metabolisation appears to be a function of the concentration. The induction of P-450 enzymes by the higher PCB load is likely to leave only the most recalcitrant congeners; most of these have a higher chlorine content. In the present study, the parallelism between levels of total PCBs and proportions of highly chlorinated congeners could also be observed, in the same individual, over the course of lactation, in maternal and pup serum and, to a lesser extent, in the inner blubber. Indeed, the total PCB concentration increased with time of lactation in these compartments (Debier et al. 2003). Accordingly, the PCB pattern in outer blubber, which did not vary with time, corresponded to constant values in total PCB concentrations between 
early and late lactation. In the case of milk, however, no difference of pattern of these congeners was observed between early and late lactation despite an increase in the total PCB levels. This phenomenon indicates that the concentrations of individual congeners increase in the same proportion as PCB-153, in contrast to what was seen in the previous compartment of transfer. It supports the assumption of a barrier against the higher chlorinated congeners at the mammary gland or a greater affinity of the lipids present in the milk for the lower chlorinated PCBs.

The composition of PCBs also differed between compartments, higher chlorinated congeners being encountered in relatively higher amounts in blubber and pup serum compared to milk and, to a lesser extent, maternal serum. Outer blubber, which is the most contaminated layer, also contained more highly chlorinated congeners than inner blubber, mainly at early lactation. Lipid composition might certainly play a role in the distribution of PCBs congeners between compartments. The higher proportion of highly chlorinated congeners in inner blubber than in maternal serum has also been reported in the literature, where it was concluded that the higher the chlorination degree, the less efficient the transfer from blubber lipid to serum lipid (Addison \& Brodie 1987). Indeed, the liposolubility of PCBs increases with the degree of chlorination. The lipid composition of serum is made of more polar lipids compared to subcutaneous lipids, which are mainly made of non-polar lipids (triglycerides) (Henderson et al. 1994). In grey seals, the fatty acid composition in milk has been shown to be different to that in maternal blubber (Grahl-Nielsen et al. 2000), which might also explain the higher proportion of lesser chlorinated PCBs and the lower proportion of highly chlorinated PCBs in milk, compared to the previous compartments of transfer. This is, however, in contradiction to the study of Addison \& Brodie (1987) on grey seals, in which the ratios of concentrations between milk lipids and serum lipids were higher for PCB-180 and -153 compared to PCB-101 and -77 .

Biomagnification in pup serum was noticed for hepta-, octa-, and nona-CBs, while the contrary was noticed for penta- and hexa-CBs. Due to the lack of performance of the detoxification system of young animals, it would be surprising that these latter congeners were metabolized and excreted. Less efficient absorption by the intestinal epithelium, or better deposition in blubber or liver than the congener 153, and even more than the hepta-, octa- and nona-CBs, might explain this. Highly chlorinated congeners appear to form less of the burden in blubber of pups compared to adults, while less chlorinated ones are present in greater proportions, as reported in Espeland et al. (1997) and in Bernt et al. (1999). The authors that did not analyze the blood compartment of the pups suggested a lower transfer of higher chlorinated PCBs from mother to pup, as well as inefficient metabolic abilities in pups, to be responsible. However, this observation could also be explained by a higher deposition of lower chlorinated compared to higher chlorinated congeners in pup tissues, possibly because of the composition of the lipids ingested, absorbed, transported and stored in the pup itself. An analysis of the blubber composition of nursing pups would be necessary in order to confirm this hypothesis.

When pup sera were compared to the sera of their mothers, it appeared that the PCB pattern of newborns was similar to that of their respective mothers. This phenomenon suggests that the placental barrier does not exert selectivity pressure against some categories of congeners in grey seals. According to Juchau (1983), all PCB congeners are indeed expected to pass across placental membranes by simple passive diffusion, due to their liposolubility, and molecular weight lower than 600. However, our results differ from those found in striped dolphins Stenella coeruleoalba, for which the concentration ratios in the blubber of the foetus compared to that of the mother gradually decreased with the increase in number of chlorine atoms (Tanabe et al. 1982). In grey seals, the PCB profile of pups then differed from their mothers following the ingestion of milk. At late lactation, the higher chlorinated congeners were present in greater amounts in pup serum compared to maternal serum.

Studies requiring blubber biopsies on nursing pups coupled with analysis of the lipid composition of the different body compartments would bring complementary information on the quantitative and qualitative transfer of PCB from mother to pup during lactation.

Acknowledgements. Long-term research on the Isle of May is supported by UK NERC's Core Research Programme. Field assistance provided by Simon Moss, Paula Redman, Sean Twiss, Kimberley Bennett, Catriona Stevenson and Susanne McCulloch during the collection of milk and blood samples is gratefully acknowledged. Funding for field work was in part provided by the Belgian National Council for Scientific Research and UK NERC Core Support to SMRU. The authors also thank Murielle Louvet and Christine Dykmans from the Laboratoire d'Ecologie animale et d'Ecotoxicologie, University of Liège (Belgium) for valuable help during the chemical analyses, as well as Prof. Philippe Baret for helpful comments on the data analyses. C.D. was a research fellow of the Belgian National Council for Scientific Research.

\section{LITERATURE CITED}

Addison RF, Brodie PF (1987) Transfer of organochlorine residues from blubber through the circulatory system to milk in the lactating grey seal Halichoerus grypus. Can J Fish Aquat Sci 44:782-786

Andersen G, Kovacs KM, Lydersen C, Skaare JU, Gjertz I, 
Jenssen BM (2001) Concentrations and patterns of organochlorine contaminants in white whales (Delphinapterus leucas) from Svalbard, Norway. Sci Total Environ 264: $267-281$

Bacon CE, Jarman WM, Costa DP (1992) Organochlorine and polychlorinated biphenyl levels in pinniped milk from the Arctic, the Antarctic, California and Australia. Chemosphere 24:779-791

Bard SM (1999) Global transport of anthropogenic contaminants and the consequences for the Artic marine ecosystem. Mar Pollut Bull 38:356-379

Beckmen KB, Ylitalo GM, Towell RG, Krahn MM, O'Hara TM, Blake JE (1999) Factors affecting organochlorine contaminant concentrations in milk and blood of northern fur seal (Callorhinus ursinus) dams and pups from St George Island, Alaska. Sci Total Environ 231:183-200

Bernhoft A, Wiig Ø, Skaare JU (1997) Organachlorines in polar bears (Ursus maritimus) at Svalbard. Environ Pollut 95:159-175

Bernt KE, Hammill MO, Lebeuf M, Kovacs KM (1999) Levels and patterns of PCBs and OC pesticides in harbour and grey seals from the St Lawrence Estuary, Canada. Sci Total Environ 243/244:243-262

Boon JP, Oostingh I, van der Meer J, Hillebrand MT (1994) A model for the bioaccumulation of chlorobiphenyl congeners in marine mammals. Environ Toxicol Pharmacol 270:237-251

Cleemann M, Riget F, Paulsen GB, de Boer J, Dietz R (2000) Organochlorines in Greenland ringed seals (Phoca hispida). Sci Total Environ 245:103-116

Debier C, Pomeroy PP, Mignolet E, Baret PV, Larondelle Y (2002) Vitamin E status and the dynamics of its transfer between mother and pup during lactation in grey seals (Halichoerus grypus) during lactation. Can J Zool 80:1-11

Debier C, Pomeroy PP, Dupont C, Joiris C, Comblin V, Le Boulengé E, Larondelle Y, Thomé JP (2003) Quantitative dynamics of PCB transfer from mother to pup during lactation in UK grey seals Halichoerus grypus. Mar Ecol Prog Ser 247:237-248

Espeland O, Kleivane L, Haugen S, Skaare JU (1997) Organochlorines in mother and pup pairs in two Arctic seal species: harp seal (Phoca groenlandica) and hooded seal (Cystophora cristata). Mar Environ Res 44:315-330

Grahl-Nielsen O, Hammill MO, Lydersen C, Wahlstrom S (2000) Transfer of fatty acids from female seal blubber via milk to pup blubber. J Comp Physiol B 170:277-283

Heidmann WA, Staats de Yanés G, Büthe A, Rüssel-Sinn H (1992) Correlation between concentration and composition of PCB mixtures in seals (Phoca vitulina). Chemosphere 24:1111-1117

Henderson RJ, Kalogeropoulos N, Alexis MN (1994) The lipid composition of selected tissues from a Mediterranean monk seal, Monachus monachus. Lipids 29:577-582

Hong CS, Calambokidis J, Bush B, Steiger GH, Shaw S (1996) Polychlorinated biphenyls and organochlorine pesticide in harbour seal pups from the inland waters of Washington State. Environ Sci Technol 30:837-844

Editorial responsibility: Otto Kinne (Editor), Oldendorf/Luhe, Germany
Hugla JL, Philippart JC, Kremers P, Goffinet G, Thomé JP (1995) PCB contamination of the common barbel, Barbus barbus (pisces, cyprinidae), in the river Meuse in relation to hepatic monooxygenase activity and ultrastructural liver change. Neth J Aquat Ecol 29:135-145

Jenssen BM, Skaare JU, Ekker M, Vongraven D, Lorentsen SH (1996) Organochlorine compounds in blubber, liver and brain in neonatal grey seal pups. Chemosphere 32: $2115-2125$

Juchau MR (1983) Disposition of chemical contaminants in maternal-embryonic/fetal systems. In: Saxena J (ed) Hazard assessment of chemicals: Current developments, Vol 2. Academic Press, New York, p 95-132

Kleivane L, Espeland O, Fagerheim KA, Hylland K, Polder A, Skaare JU (1997) Organochlorine pesticides and PCBs in the east ice harp seal (Phoca groenlandica) population. Mar Environ Res 43:117-130

Law RJ, Allchin CR, Harwood J (1989) Concentration of organochlorine compounds in the blubber of seals from eastern and north-eastern England, 1988. Mar Pollut Bull 20:110-115

Mössner S, Ballschmiter K (1997) Marine mammals as global pollution indicators for organochlorines. Chemosphere 34: 1285-1296

Muir DCG, Norstrom RI, Simon M (1988) Organochlorine contaminants in Arctic marine food chains: accumulation of specific polychlorinated biphenyls and chlordane-related compounds. Environ Sci Technol 22:1071-1079

Pomeroy PP, Green N, Hall AJ, Walton M, Jones K, Harwood J (1996) Congener-specific exposure of grey seal (Halichoerus grypus) pups to chlorinated biphenyls during lactation. Can J Fish Aquat Sci 53:1526-1534

Ross PS (2000) Marine mammals as sentinels in ecological risk assessments. Human Ecol Risk Assess 6:29-46

Ross PS, De Swart RL, Addison R, Van Loveren H, Vos J, Osterhaus A (1996) Contaminant-induced immunotoxicity in harbour seals: wildlife at risk? Toxicology 112:157-169

Safe SH (1994) Polychlorinated biphenyls (PCBs): environmental impact, biochemical and toxic responses, and implications for risk assessment. Crit Rev Toxicol 24:87-149

SAS/STAT (1990) User's guide, Vol 2 GLM-VARCOMP Version 6, 4th edn. SAS Institute, Cary, NC

Tanabe S, Tatsukawa R, Maruyama K, Miyazaki N (1982) Transplacental transfer of PCBs and chlorinated hydrocarbon pesticides from the pregnant striped dolphin (Stenella coeruleoalba) to her fetus. Agric Biol Chem 46(5): 1249-1254

Tanabe S, Sung JK, Choi DY, Baba N, Kiyota M, Yoshida K, Tatsukawa R (1994) Persistent organochlorine residues in northern fur seal from the Pacific coast of Japan since 1971. Environ Pollut 85:305-314

Wolkers J, Burkow IC, Lydersen C, Dahle S, Monshouwer M, Witkamp RF (1998) Congener specific PCB and polychlorinated camphene (toxaphene) levels in Svalbard ringed seals (Phoca hispida) in relation to sex, age, condition and cytochrome P450 enzyme activity. Sci Total Environ 216: $1-11$

Submitted: February 22, 2002; Accepted: November 19, 2002 Proofs received from author(s): January 16, 2003 